\title{
Twin Helicenes Twist Benzene
}<smiles>Brc1c(Br)c(Br)c(Br)c(Br)c1Br</smiles>

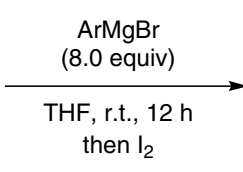<smiles>Brc1c(Br)c(Br)c(Br)c(Br)c1Br</smiles>

1. $t$-BuLi (4.5 equiv) 2. $\mathrm{CIP}\left(\mathrm{NEt}_{2}\right)_{2}$ (2.8 equiv)

1

$222 \%$ yield

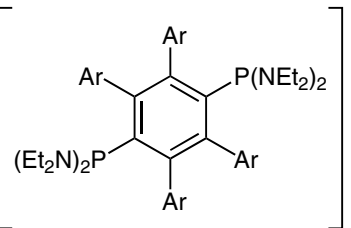

3
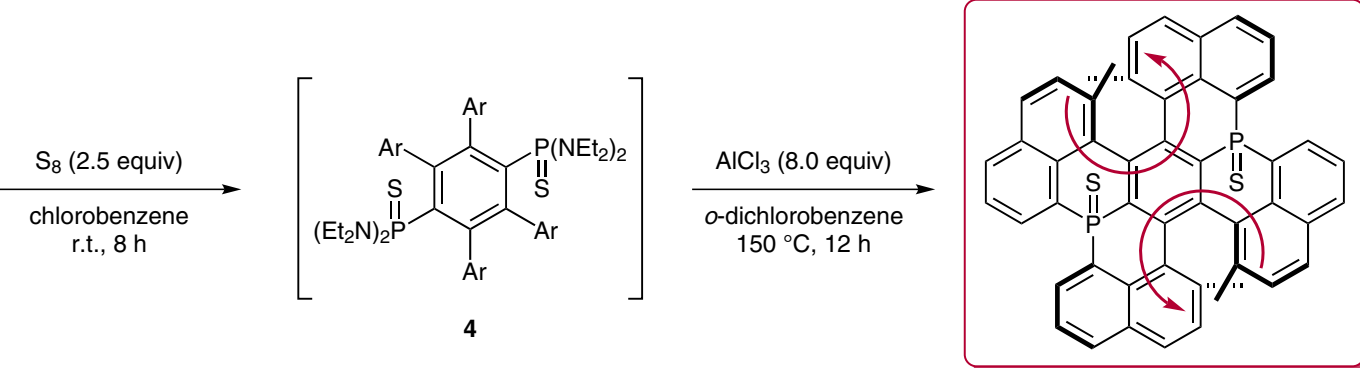

5 10\% yield from 2

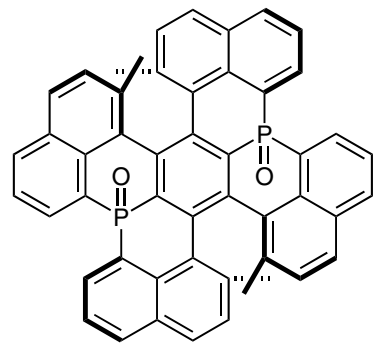

$675 \%$ yield

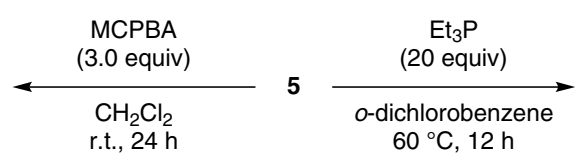

$60{ }^{\circ} \mathrm{C}, 12 \mathrm{~h}$

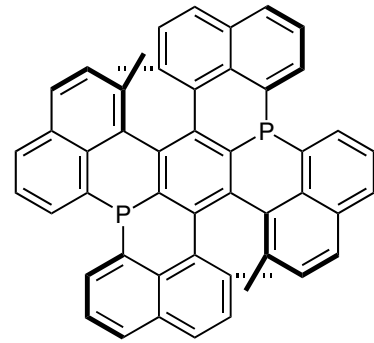

$789 \%$ yield
Significance: The authors report a new approach to construct distorted benzene rings by constraining a benzene ring between two opposing [5]helicenes. Double helicene $\mathbf{5}$ was synthesized via a tandem intramolecular phospha-Friedel-Crafts reaction. By X-ray crystallography, the central benzene ring of $\mathbf{5}$ was found to possess a bending angle of $23^{\circ}$, and the sulfur atoms were found to be in a cis arrangement.
Comment: Distorted double helicene $\mathbf{5}$ can be desulfurized with triethylphosphine to yield bis(phosphine) 7 , which could find potential use as a $\mathrm{C}_{2}$ symmetric ligand for bimetallic complexes, following separation of enantiomers. 